\title{
PENGARUH PENGGUNAAN LIMBAH BAJA TERHADAP KUAT KARAKTERISTIK BETON
}

\author{
Ronald Simatupang, Olga Pattipawaej, Tan Lie Ing, Deni Setiawan \\ Jurusan Teknik Sipil, Fakultas Teknik, Universitas Kristen Maranatha \\ Jalan Prof. drg. Suria Sumantri, MPH., No. 65, Bandung, 40164 \\ E-mail: ronald_simatupang@yahoo.com
}

\begin{abstract}
ABSTRAK
Beton merupakan salah satu material konstruksi yang banyak digunakan pada berbagai macam elemen struktur bangunan seperti kolom, balok, pelat, dan lain sebagainya. Kuat tekan tinggi, kaku, dan penghantar listrik yang rendah, merupakan karakteristik yang dimiliki beton, sehingga beton banyak digunakan dalam perencanaan elemen struktur. PS Ball sebagai produk akhir sangat seragam (koefisien keseragaman: 1,22 dibandingkan dengan pasir: 1,64) dengan kekuatan tekan yang lebih besar (161\% lebih tinggi dari pasir), tingkat kekerasan 740 Vickers (62 Rockwell). PS Ball dapat digunakan sebagai pengganti garnet atau copper slag dan terkadang sebagai pengganti steel ball / steel shot. Tujuan penelitian ini adalah mempelajari dan membandingkan perilaku material beton dengan menggunakan PS Ball dan material beton tanpa menggunakan PS Ball. Berdasarkan hasil pengujian kuat tekan beton yang menggunakan PS Ball dan beton yang tanpa menggunakan PS Ball diperoleh bahwa PS Ball bisa digunakan dalam campuran beton. Hal ini bisa terlihat dengan meningkatnya kuat tekan beton yang menggunakan PS Bal .
\end{abstract}

Kata kunci: Limbah baja, Kuat tekan.

\section{PENDAHULUAN}

Beton merupakan salah satu material konstruksi yang banyak digunakan pada berbagai macam elemen struktur bangunan seperti kolom, balok, pelat, dan lain sebagainya. Kuat tekan tinggi, kaku, dan penghantar listrik yang rendah, merupakan karakteristik yang dimiliki beton, sehingga beton banyak digunakan dalam perencanaan elemen struktur.

Saat ini telah terjadi peningkatan suhu dunia secara global maka diperlukan inovasi dalam Teknik Sipil yaitu dengan menggunakan bahan beton yang ramah lingkungan. Salah satu bahan yang akan diteliti yaitu dengan menggunakan limbah dari produksi baja dalam campuran beton. Pesatnya perkembangan pembangunan pada saat ini, menyebabkan semakin meningkatnya permintaan akan kebutuhan beton. Seiring meningkatnya kebutuhan akan beton maka diperlukan campuran beton yang ramah lingkungan dan memiliki nilai ekonomis sehingga mampu memberikan kontribusi dalam mengurangi pemanasan global yang meningkat.

PS Ball sebagai produk akhir sangat seragam (koefisien keseragaman: 1,22 dibandingkan dengan pasir: 1,64) dengan kekuatan tekan yang lebih besar (161\% lebih tinggi dari pasir), tingkat kekerasan 740 Vickers (62 Rockwell). PS Ball dapat digunakan 
sebagai pengganti garnet atau copper slag dan terkadang sebagai pengganti steel ball / steel shot. Tujuan penelitian ini adalah mempelajari dan membandingkan perilaku material beton dengan menggunakan PS Ball dan material beton tanpa menggunakan PS Ball.

\section{PS Ball}

Slag EAF merupakan produk samping dengan volume besar yang terbentuk dalam proses pembuatan baja (15-20\% dari kapasitas baja cair) dimana masih mengandung sisasisa metal. Penanganan slag ini sebelumnya sulit dan metodenya tidak efisien.

Teknologi slag atomizing (Slag Atomizing Technology: SAT) merupakan sistem baru untuk membentuk slag cair menjadi butiran kecil (atomize) dari Electric Arc Furnace (EAF) dengan efisiensi tinggi. Material hasil dari proses SAT berbentuk bola dengan diameter dan ukuran yang berbeda-beda, dan disebut PS (Precious Slag) ball.

SAT plant pertama beroperasi pada 1997 di Korea, sejak itu total kapasitas terpasang telah meningkat menjadi 1,12 juta ton. Kapasitas yang sedang dibangun dan diproyeksikan akan direalisasikan pada 2009 di Korea Selatan, Afrika Selatan, Malaysia, Thailand, Taiwan, Indonesia, Iran, Vietnam dan AS berjumlah 3,4 juta ton. Tanggal 1 Desember 2008 SAT Plant di PT Purna Baja Harsco (di dalam kawasan pabrik PT Krakatau Steel) mulai beroperasi, dengan kapasitas 5.000 ton per bulan.

SAT merupakan proses merubah slag cair $\left(1500-1550^{\circ} \mathrm{C}\right)$ menjadi bola-bola kecil dengan diameter berkisar antara 0.1 hingga $4.5 \mathrm{~mm}$. Prosesnya berupa sistem hembusan angin berkecepatan tinggi dengan katalis dan air pada aliran slag cair yang ditumpahkan melalui tundish menuju slag pitt. Dengan bantuan air, aliran udara berkecepatan tinggi menghasilkan pertukaran panas yang cepat yang merubah aliran slag menjadi bola-bola (ps ball) dengan permukaan yang mengkilap. Struktur PS Ball dipisahkan berdasarkan ukurannya dalam suatu mesin pengayak. PS Ball memiliki 4 ukuran dari butir kasar sampai dengan butir halus:
1. 4-10 MESH
2. 10-20 MESH
3. 20-40 MESH
4. 40-200 MESH

PS Ball produk ramah lingkungan hasil olahan limbah B3 yang dapat digunakan untuk material blasting sebagai pengganti pasir kuarsa. Pada Gambar 1 dapat dilihat proses produksi dari PS Ball. 


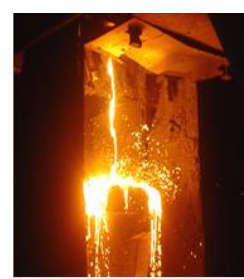

Slag (EAF, LF)

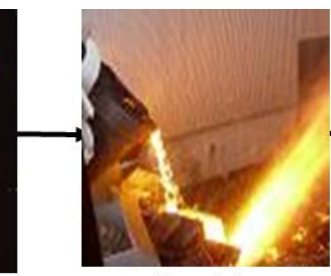

Atomizing

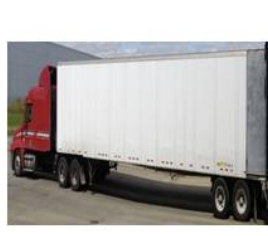

Transporting
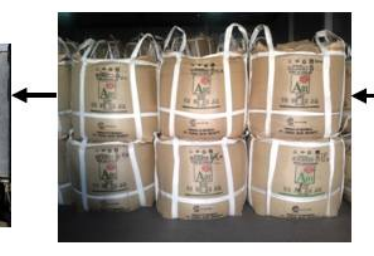

Packaging

Gambar 1. Proses Produksi PS Ball. (sumber: PT. Purna Baja)

Dalam proses SAT, slag cair didinginkan dengan cepat oleh udara dan air berkecepatan tinggi. Berbagai unsur tidak stabil membentuk $\mathrm{CaO}-\mathrm{Fe}_{2} \mathrm{O}_{3}, \mathrm{SiO}_{2}-\mathrm{Fe}_{2} \mathrm{O}_{3}$ dan $\mathrm{Mg}-\mathrm{Fe}_{2} \mathrm{O}_{3}$. Tidak ada $\mathrm{CaO}$ bebas di dalam produk, dan permukaan akan mengkilap dengan adanya struktur spinel. Struktur spinel merupakan bentuk kombinasi dari CaO$\mathrm{Fe}_{2} \mathrm{O}_{3}, \mathrm{CaO}-\mathrm{SiO}_{2}$. Pada Gambar 2 dapat dilihat bentuk butiran dari PS Ball.
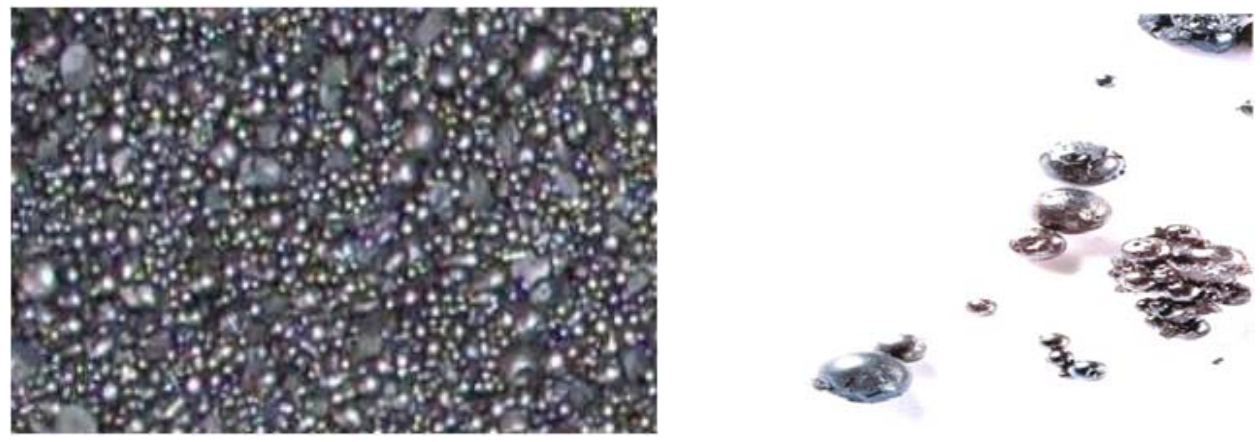

Gambar 2. Butiran PS Ball. (sumber: PT. Purna Baja)

\subsection{Karakteristik PS Ball}

PS Ball adalah singkatan dari Precious Slag Ball, material baru yang dihasilkan dari slag EAF. PS Ball memiliki permukaan mengkilap dengan struktur spinel yang 
stabil. PS Ball berbentuk bulat dengan diameter antara 0.1 sampai $4.5 \mathrm{~mm}$, material dengan tidak ada kapur bebas.

PS Ball cocok untuk berbagai penerapan, berkat sifat fisik dan kimianya. Hal penting adalah fakta bahwa PS Ball tidak berbahaya dan ramah lingkungan yang dihasilkan oleh teknologi yang bebas pengaruh negatif terhadap lingkungan. Struktur kimiawi dari PS Ball dapat dilihat pada Gambar 3.

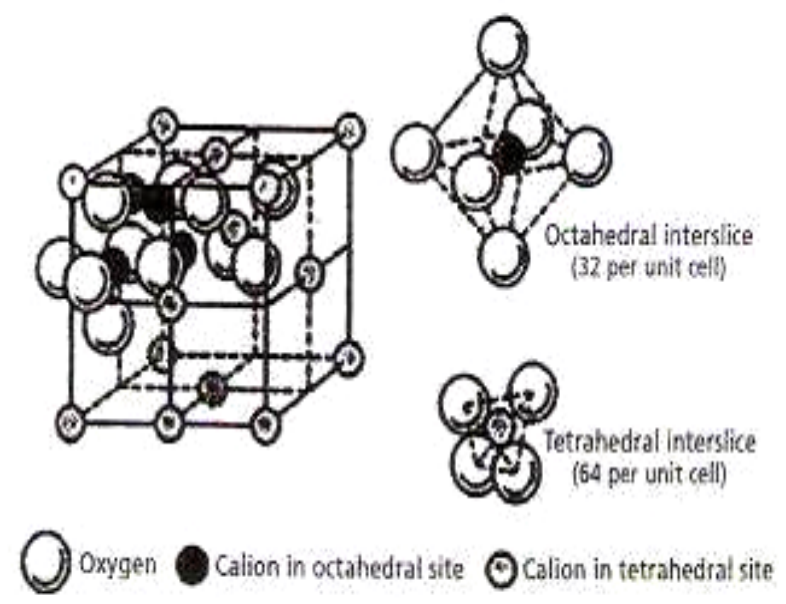

Gambar 3. Struktur Spinel PS Ball. (sumber: PT. Purna Baja)

Struktur spinel merupakan ciri utama material ini, struktur fisik dan kima yang stabil yang menghilangkan alasan polusi. Nilai persentase kandungan kimiawi dari PS Ball dapat dilihat pada Tabel 1

Tabel 1. Persentase Kandungan Kimiawi PS Ball. (sumber: PT. Purna Baja)

\begin{tabular}{|c|c|}
\hline Kandungan Kimia / Ciri Fisik & Nilai \\
\hline $\mathrm{T}-\mathrm{Fe}$ & $20,83 \%$ \\
$\mathrm{M}-\mathrm{Fe}$ & $<0,10 \%$ \\
$\mathrm{FeO}$ & $3,35 \%$ \\
$\mathrm{Fe}_{2} \mathrm{O}_{3}$ & $26,06 \%$ \\
$\mathrm{SiO}_{2}$ & $12,69 \%$ \\
$\mathrm{CaO}$ & $40,30 \%$ \\
$\mathrm{Al}_{2} \mathrm{O}_{3}$ & $2,20 \%$ \\
$\mathrm{MgO}$ & $7,95 \%$ \\
\hline
\end{tabular}




\begin{tabular}{|c|c|}
\hline Kandungan Kimia / Ciri Fisik & Nilai \\
\hline $\mathrm{Na}_{2} \mathrm{O}$ & $<0,10 \%$ \\
Kekerasan & $739,8 \mathrm{HVC}$ \\
Diameter & $0,1-4,5 \mathrm{~mm}$ \\
Massa Jenis & $2,3 \mathrm{~kg} / \mathrm{L}$ \\
Permeabilitas Air & $530 \mathrm{~cm} / \mathrm{s}$ \\
Kekuatan Tekan & $323 \mathrm{~kg} / \mathrm{cm}^{3}$ \\
\hline
\end{tabular}

Karakteristik dari material PS Ball dibandingkan dengan material lain yang ada dapat diihat pada Tabel 2.

Tabel 2. Karakteristik Material PS Ball. (sumber: PT. Purna Baja)

\begin{tabular}{|c|c|c|c|c|c|}
\hline Classification & PS Ball & Sand & Garnet & Glass Bead & Steel Ball \\
\hline $\begin{array}{c}\text { Actual Specific } \\
\text { Gravity }\end{array}$ & 3.45 & 2.62 & 4.2 & 2.6 & 7.2 \\
\hline $\begin{array}{c}\text { Mohs Hardness } \\
\begin{array}{c}\text { Rockwell } \\
\text { Hardness (HRC) }\end{array}\end{array}$ & 4.5 & 5.5 & 7.5 & 5 & 8.5 \\
\hline $\begin{array}{c}\text { Brightness } \\
\text { (quality grade) }\end{array}$ & Verygood & Normal & Good & Normal & Verygood \\
\hline Reusability & $1-3$ times & One time & $1-3$ times & One time & 5 -7 times \\
\hline
\end{tabular}

\subsection{Keuntungan Penggunaan PS Ball}

PS Ball sangat unggul dibanding pasir dalam hal kekuatan tekan, kekerasan, dan anti-weathering. Strukturnya sangat kuat, tahan cuaca dan tidak mudah aus dengan bentuk bulat mengkilap. Sebagai material baru, PS Ball memiliki keunggulan sifat-sifat fisik dan kimia yang memberikan kemampuan untuk berbagai penerapan yang luas, seperti pelapis genting metal, manholes, amplas, pemadatan jalan, bahan pemberat, peredam suara dan pelindung radiasi, campuran semen, bahan lantai, pemadat tanah, tiang 
pancang, pengolahan air dan air buangan, bahan filter, bahan lantai yang tidak licin, bata dan bahan beton prefabrikasi, ubin yang tidak mudah aus, campuran aspal, dan lain-lain.

PS Ball sebagai produk akhir sangat seragam (koefisien keseragaman: 1,22 dibandingkan dengan pasir: 1,64) dengan kekuatan tekan yang lebih besar (161\% lebih tinggi dari pasir), tingkat kekerasan 740 Vickers (62 Rockwell). PS Ball dapat digunakan sebagai pengganti garnet atau copper slag dan terkadang sebagai pengganti steel ball / steel shot. Dengan tingkat keseragaman tersebut dan kekuatan tekan yang sangat maka material PS Ball dapat digunakan dalam aplikasi teknik sipil dalam hal ini digunakan sebagai bahan pengisi dalam campuran beton untuk mendapatkan kuat tekan yang tinggi.

\section{Hasil Pengujian}

Pengujian dilakukan dengan menambahkan limbah baja dalam campuran beton dalam hal ini digunakan sebagai campuran pengisi (filler) dalam campuran beton. Proporsional campuran yang digunakan yaitu 10\%, 20\%, 30\%, 40\% dan 50\% dari berat pasir.

\subsection{Komposisi campuran beton}

Berdasarkan hasil pengujian yang telah dilakukan maka didapatkan campuran beton yang digunakan untuk mendapatkan kuat tekan 25 MPa ditampilkan pada Tabel 3.

Tabel 3. Komposisi Campuran Beton.

\begin{tabular}{|c|c|c|}
\hline No & Jeni Material & Berat $(\mathrm{kg} / \mathrm{m} 3)$ \\
\hline 1 & Semen & 372.55 \\
\hline 2 & Air & 190 \\
\hline 3 & Agregat Kasar & 1181.219 \\
\hline 4 & Agregat Halus & 6.262 \\
\hline
\end{tabular}

\subsection{Hasil pengujian kuat tekan beton normal}

Hasil pengujian tekan beton dengan benda uji silinder dapat dilihat pada Tabel 4. Berdasarkan Tabel 4 terlihat bahwa campuran beton normal yang digunakan dalam perhitungan memenuhi target yang diinginkan yaitu sebesar 25MPa. 
Tabel 4. Kuat Tekan Rencana Beton Normal.

\begin{tabular}{|c|c|c|c|c|c|}
\hline Beton normal kuat & \multicolumn{5}{|c|}{ Umur Rencana } \\
\cline { 2 - 6 } $\begin{array}{c}\text { tekan rencana 25 } \\
\text { Mpa }\end{array}$ & 3 hari & 7 hari & 14 hari & 21 hari & 28 hari \\
\hline 25 & 10.83 & 15.18 & 21.35 & 24.80 & 27.07 \\
\hline
\end{tabular}

\subsection{Hasil Pengujian Kuat Tekan Beton dengan Menggunakan PS Ball}

Hasil pengujian tekan beton dengan benda uji silinder dengan menggunakan tambahan PS Ball sebagai pengisi dalam beton dapat dilihat pada Tabel 5. Berdasarkan Tabel 5 terlihat perubahan kuat tekan rencana beton dengan persentase PS Ball yang berbeda.

Tabel 5. Kuat Tekan Beton Dengan Persentase Kadar PS Ball yang Berbeda.

\begin{tabular}{|c|c|c|c|c|c|c|}
\hline \multirow{2}{*}{ No } & Kadar & \multicolumn{5}{|c|}{ Kuat tekan rata-rata (Mpa) } \\
\hline & PS Ball & 3 hari & 7 hari & 14 hari & 21 hari & 28 hari \\
\hline 1 & $10 \%$ & 14.90 & 19.90 & 21.75 & 18.54 & 19.49 \\
\hline 2 & $20 \%$ & 8.87 & 16.71 & 18.75 & 21.58 & 22.69 \\
\hline 3 & $30 \%$ & 21.31 & 28.28 & 27.86 & 34.86 & 36.61 \\
\hline 4 & $40 \%$ & 11.56 & 18.20 & 19.35 & 22.92 & 24.09 \\
\hline 5 & $50 \%$ & 13.64 & 19.94 & 21.92 & 23.14 & 24.33 \\
\hline
\end{tabular}

Berdasarkan Tabel 5 dapat dilihat peningkatan kuat tekan beton dengan menggunakan PS Ball, peningkatan yang signifikan terjadi dengan penambahan PS Ball sebesar 30\% dari berat pasir dibandingan dengan beton normal. Pada campuran PS Ball 10\%, 20\%, 40\% dan 50\% mengalami penurunan kuat tekan. Pada Tabel 5 dapat terlihat peningkatan kuat tekan beton umur 28 hari dibandingkan dengan beton normal yang didesain. Peningkatan yang terjadi sebanyak 1.35 kali dari kuat tekan beton normal yang diuji. Pada Tabel 6 dapat terlihat perbandingan peningkatan kuat tekan beton dengan menggunakan PS.Ball dibandingkan dengan kuat tekan beton normal. 
Tabel 6. Peningkatan Kuat Tekan Beton.

\begin{tabular}{|c|l|c|c|}
\hline No & Keterangan & $\begin{array}{c}\text { Kuat } \\
\text { Tekan } \\
(\mathrm{Mpa})\end{array}$ & $\begin{array}{c}\text { Perbandingan Kuat } \\
\text { Tekan Dengan Beton } \\
\text { Normal }\end{array}$ \\
\hline 1 & Beton Normal & 27.07 & - \\
\hline 2 & Beton $10 \%$ PS Ball & 19.49 & 0.72 \\
\hline 3 & Beton 20\% PS Ball & 22.69 & 0.84 \\
\hline 4 & Beton 30\% PS Ball & 36.61 & 1.35 \\
\hline 5 & Beton 40\% PS Ball & 24.09 & 0.89 \\
\hline 6 & Beton 50\% PS Ball & 24.33 & 0.90 \\
\hline
\end{tabular}

\section{Simpulan}

Dari hasil pengujian maka dapat diperoleh beberapa kesimpulan yaitu:

1. Penggunaan PS Ball dapat digunakan sebagai filler dalam campuran beton.

2. Terjadi peningkatan kuat tekan maksimum beton umur 28 hari yang menggunakan kadar PS Ball dengan penambahan 30\% dari PS.Ball. Peningkatan kuat tekan beton dengan menggunakan 30\% PS Ball mencapai 1.35 kali lebih tinggi dari kuat tekan beton normal.

3. Terjadi penurunan kuat tekan beton umur 28 hari yang menggunakan kadar PS Ball 10\%, 20\%, 40\%, 50\% dibandingkan dengan campuran beton tanpa menggunakan PS Ball.

4. Penurunan optimum kuat tekan beton yang menggunakan PS Ball terjadi pada saat mencampur 10\% PS Ball dalam campuran beton. Penurunan kuat tekan beton dengan menggunakan 10\% PS Ball mencapai 0.75\% kali lebih rendah dari kuat tekan beton normal.

\section{KETERANGAN}

Sebagaian materi yang ada didalam jurnal ini akan digunakan dalam seminar internasional EACEF 2013 di National University of Singapore (NUS) 26-28 Juni 2013. 


\section{DAFTAR PUSTAKA}

1. ACI 318-02, "Building Codes Requirment for Structural Concrete and Commentary”, ACI Committee, 2002.

2. ACI T1.1-01, "Acceptance Criteria for Moment Frames Based on Structural Testing”, ACI Innovation Task Group 1 and Collaborates.

3. ASTM A 615M - 93, "Standard Specification for Deformed and Plain BilletSteel Bars for Concrete Reinforcement”, Annual Book of ASTM Standards, Volume 01.04, pp. 303-308

4. ASTM A 706 M - 93a, "Standard Specification for Low-Alloy Steel Deformed Bars for Concrete Reinforcement”, Annual Book of ASTM Standards, Volume 01.04, pp. 353-357.

5. Annual Book of ASTM Standart, Destignation C 39a - 93, "Standart Specification for Concrete Agregat”.

6. Annual Book of ASTM Standart, Destignation C 78 - 94, "Standart Practice for Making and Curing Concrete Test Specimen in Laboratory”.

7. Astana D. Yulius, 2000, "Pengaruh Kombinasi Copper Slag dan Pasir Lumajang dalam Campuran Beton yang mengandung Fly Ash terhadap Kuat Tekan dan Berat Volume”, Tugas Akhir Sarjana FTSP - UPN “Veteran” Jawa Timur.

8. Aulia Hamzah, "Sifat Fisik dan Mekanik Beton Mutu Tinggi dengan Campuran Copper slag”, Tugas Akhir S - 1, FTSP, ITS, 1999.

9. Mac Gregor, James dan Wight, James, K., “Reinforced Concrete Mechanic and Design Fourth Edition”, Prentice Hall, New Jersey, 2005.

10. Park, R dan Paulay, T., "Reinforced concrete Structures”, John Wiley, Canada, 1975.

11. SNI 03 - 2847 - 2002, "Tata Cara Perhitungan Struktur Beton untuk Bangunan Gedung”, 2002. 